DOI: $10.20472 / \mathrm{IAC} .2017 .33 .066$

SARBJIT SINGH

Institute of Management Technology, India

\title{
ANALYSIS OF INVENTORY POLICY FOR PERISHABLE GOODS HAVING CONSTANT DEMAND
}

\begin{abstract}
:
One of the major problems of retailers is when to order and how much to order their products so that the total inventory cost is minimized i.e. their operating profit is maximized. This study focuses on the inventory management of perishable items having constant demand. Firstly, the mathematical model for perishable items have been framed and then using the principle of maximaminima the optimal cycle time equation has been obtained. Also using simulation the best possible solution has been obtained for the various cases. By using the above model retailer can easily decide his inventory cycle time and optimal ordering quantity. The above model can be converted into the classical EOQ model if nonperishable items are considered. Otherwise, also it follows the classical EOQ principle which states that the optimal order quantity is obtained when ordering cost is equal to the carrying cost
\end{abstract}

\section{Keywords:}

Deterioration, Optimality, Sensitivity

JEL Classification: C44 